\title{
The Development Paradox of Regional low-carbon Economy in Guangdong and Relevant Differential Treatment Measures
}

\author{
Yu Zhang, Guangrong Sun \\ Institute of Public Administration, \\ South China Agricultural University, \\ Guangzhou, China
}

\begin{abstract}
Based on environmental Kuznets curves, factors influencing development of regional low-carbon economy could be concluded as: scale effect, technology effect and structure effect of economic growth. Scale effect of economic growth has negative influence on environmental quality while technology effect and structure effect of economic growth effectively improve environmental quality. It has been found in measurement and calculation of the index "Elasticity Coefficient of Carbon Emission Ratio" the development paradox of whether to speed up scale effect of economic growth first or to accomplish the goal of energysaving and emission-reduction first in backward areas in Guangdong. The treatment measures that help achieve both goals are to construct the market-based strategy "Orderly Industry Transfer" and adopt the differential measure "The Government Providing Macroscopic Policy Guidance" at the same time, so as to change the division of labor and layout of inter-regional industrial structure and improve influence of structure effect and scale effect on regional carbon reduction potential.
\end{abstract}

Keywords-environmental Kuznets curve; regional lowcarbon economy; development paradox

\section{INTRODUCTION}

\section{A. Description of the problem}

In the Copenhagen climate summit in 2009, China made the commitment to reduce $\mathrm{CO}_{2}$ emission intensity (namely $\mathrm{CO}_{2}$ emission for unit GDP) by $40-45 \%$ in 2020, in comparison to $\mathrm{CO}_{2}$ emission intensity in 2005. With accelerating industrialization and urbanization in China, however, development of high energy-consuming industries has aggravated energy consumption, so carbon emission has been increasing each year. Therefore, the National Twelfth Five-Year Plan clearly points out that it would be taken as an important focal point of future harmonious development of economy and the society to speed up the transformation of the economic growth mode, the most important task of which was to adjust the industrial structure. How do economic growth and industrial structure adjustment influence carbon emission? This paper analyzes current situation and existing problems of implementation of low-carbon economy in four regions - the Pearl River Delta, western Guangdong, eastern Guangdong, and northern Guangdong.

\section{B. Type of regional low-carbon economy development in Guangdong}

Guangdong province is divided into four economic regions: the Pearl River Delta, the East Wing, the West Wing and the mountainous areas of northern Guangdong. Cities in the East Wing have no obviously competitive industries in terms of natural resource endowment. Cities in the West Wing are mainly advantageous in petroleum and natural gas industry and other resource-related industries. And competitive industries in the mountainous areas of northern Guangdong mainly include extractive industry, resource processing industry and other resourcerelated industries. The past 30 years of reform and opening-up have witnessed remarkable progresses in both economic gross and per capita index in each region in Guangdong, but economic gap between these regions is getting more and more obvious. Economic gross in the East Wing is $8.38 \%$ of economic gross of the Pearl River Delta, economic gross in the West Wing is $9.25 \%$ of economic gross of the Pearl River Delta and economic gross in the mountainous areas of northern Guangdong is 8.35\% of economic gross of the Pearl River Delta. Per capita GDP in the Pearl River Delta is 4.07 times of per capita GDP in the East Wing, 3.49 times of per capita in the West Wing and 4.03 times of per capital in the mountainous areas of northern Guangdong [1]. Therefore, per capita GDP differs significantly in these regions. Per capita GDP in the Pearl River Delta is far above per capita GDP in the East Wing, the West Wing and the mountainous areas of northern Guangdong.

\section{THE DEVELOPMENT PARADOX OF REGIONAL LOW- CARBON ECONOMY IN GUANGDONG AND ITS EMPIRICAL TEST}

\section{A. The development paradox of regional low-carbon economy}

Type of regional economy in Guangdong indicates that the East Wing, the West Wing and the mountainous areas of northern Guangdong are relatively backward regions in our province and need faster development. One of the general regional development strategies in our province in the Twelfth Five-Year Plan is to gradually narrow the gap in regional development. Therefore, faster economic growth needs to be realized in the East Wing, the West Wing and the mountainous areas of northern 
Guangdong than in the Pearl River Delta. However, carbon emission is higher in these relatively backward regions: the East Wing, the West Wing and the mountainous areas of northern Guangdong. Rich energy resources and faster economic growth might indicate higher carbon emission. This is the paradox of regional low-carbon economy referred to in this paper. "Higher Carbon Emission" in Guangdong indicates slower decrease of energy consumption for unit GDP or carbon emission for unit GDP. Once the paradox stands, the general emission reduction targets might not be realized in implementation of low-carbon economy development, or the general emission reduction targets for the entire province might have to be lowered, or economic growth rate might decrease due to energy conservation and emission reduction.

\section{B. Empirical test of the development paradox of regional low-carbon economy in Guangdong}

In order to test and verify existence of the development paradox of regional low-carbon economy in Guangdong, the authors of this paper have designed the index "Elasticity Coefficient of Carbon Emission Ratio," which is ratio of changes of the proportion of carbon emission in a certain prefecture-level city in carbon emission in the entire province to changes of the proportion of the prefecture-level city in the entire province. The reason for this is that the proportion of carbon emission in a certain prefecture-level city in carbon emission in the entire province will certainly increase faster than the proportion of economic gross in the prefecture-level city in economic gross in the entire province, if the prefecture-level city gains faster economic growth at the price of higher carbon emission. The computational formula for this is:

$$
\mathrm{CEG}=\frac{\mathrm{CP}_{\mathrm{it}} / \mathrm{CP}_{\mathrm{it}-1}}{\mathrm{GDPP}_{\mathrm{it}} / \mathrm{GDPP}_{\mathrm{it}-1}}=\frac{\left(\mathrm{CP}_{\mathrm{it}}-\mathrm{CP}_{\mathrm{it}-1}\right) / \mathrm{CP}_{\mathrm{it}-1}}{\left(\mathrm{GDPP}_{\mathrm{it}}-\mathrm{GDPP}_{\mathrm{it}-1}\right) / \mathrm{GDP}_{\mathrm{it}-1}}
$$

The elasticity coefficient has the same construction principle as other economic elasticity coefficients. CEG represents elasticity coefficient of carbon emission ratio. $\mathrm{CP}_{\text {it }}$ represents the ratio of carbon emission in the prefecture-level city i to carbon emission in the entire province in the current period. $\mathrm{CP}_{\mathrm{it}-1}$ represents the ratio of GDP in the prefecture-level city i to GDP in the entire province in the current period. $\mathrm{GDPP}_{\mathrm{it}-1}$ represents the ratio of GDP in the prefecture-level city i to GDP in the entire province in the previous period. Since annual data are subject to influence of accidental factors, the overall trend in a longer period is more valuable. In this paper, the period of the "11th Five-Year Plan" is chosen, for observation of overall changes of CEG coefficient in each region in Guangdong. The computational formula for this is:

$$
\mathrm{CEGi}_{\mathrm{i} 2006-2010}=\frac{\mathrm{CP}_{\mathrm{i} 2006-2010} / \mathrm{CP}_{\mathrm{i} 2005}}{\mathrm{GDPP}_{\mathrm{i} 2005-2010} / \mathrm{GDPP}_{\mathrm{i} 2005}}=\frac{\left(\mathrm{CP}_{\mathrm{i} 2010}-\mathrm{CP}_{\mathrm{i} 2005}\right) / \mathrm{CP}_{\mathrm{i} 2005}}{\left(\mathrm{GDPP}_{\mathrm{i} 2010}-\mathrm{GDPP}_{\mathrm{i} 2005}\right) / \mathrm{GDP}_{\mathrm{i} 2005}}
$$

$\mathrm{CEG}_{\mathrm{i} 2006-2010}$ represents CEG coefficient in the prefecture-level city i during the 11th Five Year Plan, so 2005 should be taken as year $\mathrm{t}-1 . \triangle \mathrm{CP}_{2005-2010}$ represents overall changes of CP from 2005 to 2010. $\triangle \mathrm{GDPP}_{2005-}$
2010 indicates overall changes of GDPP from 2005 to 2010. The computing results are stated as follows. CEG coefficients in western Guangdong and northern Guangdong are 1.55 and 1.65, CEG coefficient in eastern Guangdong is -1.78 , and CEG coefficient in the Pearl River Delta is 1.02. It deserves attention that CEG coefficient is above 1 in both northern Guangdong and the Pearl River Delta, but these two coefficients indicates different economic implications. Ratio of carbon emission in both western Guangdong and northern Guangdong to carbon emission in the entire province increased. So did ratio of GDP in both these regions to GDP in China. The coefficient above 1 indicates gaining faster economic growth at the price of higher carbon emission. Both the ratio of carbon emission in the Pearl River Delta to carbon emission in the entire province and the ratio of GDP in the Pearl River Delta to GDP in the entire province decreased. The coefficient above 1 indicates faster decrease of the ratio of carbon emission in the Pearl River Delta to carbon emission in the entire province, compared to the ratio of GDP in the Pearl River Delta to GDP in the entire province, and gaining higher economic growth at the price of lower carbon emission. The ratio of carbon emission in eastern Guangdong to carbon emission in the entire province decreased while the ratio of GDP in eastern Guangdong to GDP in the entire province increased, so higher economic growth was gained at the price of lower carbon emission. Western Guangdong and northern Guangdong happen to be backward regions, where faster development is needed, so the paradox of regional lowcarbon economy exists in these regions.

The authors of this paper are concerned about any serious consequence of the paradox of regional lowcarbon economy. In the period of the "11th Five Year Plan," the intended target of reducing energy consumption for unit GDP in all the 21 prefecture-level cities in Guangdong. However, energy consumption reduction for unit GDP only by $19.1 \%$ was realized in entire Guangdong province, which was far lower than the intended target $20 \%$. This was fundamentally caused by the paradox of regional low-carbon economy. The reason for this was simple. Carbon emission intensity was higher in relatively backward western Guangdong and northern Guangdong and the ratio of economic gross in both these regions to economic gross in the entire province increased, with economic growth gained at the price of "higher carbon emission." As a natural result of this, the average energy consumption for unit GDP increased, and the "negative influence" was not offset by "positive influence" in the Pearl River Delta.

A further problem was that experience gained during the "11th Five Year Plan" indicated that larger space for carbon emission was needed in relatively backward regions for faster development. Therefore, relatively backward regions was favored in region decomposition of energy saving and consumption reducing in the entire province in the "Twelfth Five-Year Plan." Obviously, this was a "compromise" to the paradox of regional lowcarbon economy, instead of a solution to the paradox. This 
leads to the doubt whether the national target of energy saving and consumption reducing could be achieved, with local targets of energy saving and consumption reducing reached in each region in Guangdong in the periodof the "Twelfth Five-Year Plan." Therefore, relevant calculation has been performed. It is assumed that the energy saving and consumption reducing target set by the province could be achieved in each administrative unit of prefecture-level city during the "Twelfth Five-Year Plan" and that economy grows at the speed of $9 \%$ in the eastern Pearl River Delta, 8\% in eastern Guangdong and western Guangdong, and 9\% in cities in northern Guangdong. And carbon emission intensity in 2005 could certainly be calculated. The calculation results indicate that energy consumption for unit GDP in Guangdong will only reduce by $15.7 \%$ and the intended target $16 \%$ will not be achieved in 2015. This research continues to place people under such pressing conditions. Is it more important to gain faster development in backward regions or to achieve provincial energy saving and emission reduction targets?

\section{General ways of realizing regional low-carbon economy}

The nature of low-carbon economy, as an economic form, is the transformation from traditional economic form to a new economic form. Economic development is emphasized first in low-carbon economy, the nature of which is to ensure sustainable development of national economy and the society with low energy consumption, low emission and low pollution. Low-carbon economy aims at realizing economic development and low-carbon emission at the same time, instead of giving up development or growth to achieve low-carbon target. Increase of low-carbon economy level indicates improving productivity and energy conversion efficiency, realizing low-carbon energy and raising low-carbon technology level. At present, economic development remains the primary task in backward regions in future development, due to the development paradox of lowcarbon economy in backward regions in Guangdong. It is impossible to realize regional carbon emission reduction potential and fulfill regional carbon emission reduction tasks. Therefore, the energy saving and emission reduction target could be achieved, with the market-based strategy "Orderly Industry Transfer" constructed and the differential treatment measure "The Government Providing Macroscopic Policy Guidance” adopted.

\section{DIFFERENTIAL TREATMENT MEASURES FOR REGIONAL LOW-CARBON ECONOMY DEVELOPMENT IN GUANGDONG}

The treatment measures to realize regional low-carbon economy development are to construct the market-based strategy "Orderly Industry Transfer" and to adopt the differential treatment measure "The Government Providing Macroscopic Policy Guidance.”

\section{A. About industry transfer paths}

Feasibility of industry transfer mainly involves the following:

First, it involves keeping optimizing regional industrial structure: developing advanced manufacturing industry, high and new technology industry and modern service industry, improving independent innovation capability.

Second, it involves forming reasonable interregional industry division: actively undertaking labor-intensive and resource-intensive industries and some capital-intensive industries, actively improving technology in conventional industries at the same time, developing advanced manufacturing industries conditionally, guiding corresponding industries in developing in the new region, guiding reasonable spatial arrangement of transferred industries.

Third, it involves constructing regional industry connection and interaction. Based on experience gained in orderly industry transfer in Guangdong, interregional industry connection and interaction could be promoted in two ways in orderly industry transfer, to improve harmonious regional industry development. Relocating transfer is adopted in enterprise transfer, namely, an enterprise in a certain region relocates some of its production links in another region and completes industry transfer by building a branch factory or a subsidiary company in the new region. Supporting enterprises of a certain enterprise are moved into the region along the Pearl River Delta, with the core enterprise left in the Pearl River Delta, forming close intra-industry or inter-industry interregional connection.

Finally, it also involves improving overall efficiency of regional industry development. Orderly industry transfer induces and promotes regional industrial structure optimization and adjustment. With reasonable interregional industry division and interregional industry connection and interaction, the problem of complex or disorganized industrial structure could be effectively solved, and resource allocation efficiency could be improved. Orderly industry transfer reduces interregional low-level industry competition and duplicate construction, and enhances industry development coordination. Meanwhile, orderly industry transfer directly helps improve overall efficiency of regional industry development, by solving the problem of ecological environment. In orderly industry transfer, restrictions on transfer of polluting enterprises and guidance given to enterprises on technical level and management level improvement during the transfer are emphasized, so as to reduce environmental pollution in the region into which industries are transferred and improve resource utilization efficiency. On the one hand, orderly industry transfer improves infrastructures for industry development in the new region through concentrated input, provides highquality public service and reduces external enterprise development cost. On the other hand, orderly industry transfer promotes formation and development of industry 
clusters and, further, gains and improves agglomeration economies.

\section{ACKNOWLEDGMENTS}

This paper is the periodical result of Zhang $\mathrm{Yu}$ presiding over the subject "A Study on Low-Carbon Economy Development and Carbon Emission Reduction Potential of Cities in Guangdong" (Guangdong Development and Reform Committee B5-28) of the special fund of low carbon economy development organized by Guangdong Development and Reform Committee in 2012.

\section{REFERENCE}

[1] Data source: Guangdong Statistical Yearbook 2013. Guangdong Social and Economical Statistical Information Service Center, 554, 2013. 